\title{
GAMBARAN PEMENUHAN NUTRISI PADA BALITA STUNTING UMUR 7-23 BULAN DALAM KELUARGA DI UPTD PUSKESMAS SUKOREJO
}

\author{
Triana Setijaningsih ${ }^{1)}$, Cintia Devi Nigita ${ }^{2)}$, Tri Cahyo Sepdianto ${ }^{3)}$ \\ $1 \& 3$, Jurusan Keperawatan Poltekkes Kemenkes Malang \\ 2, Mahasiswa keperawatan Poltekkes Kemenkes Malang \\ *Email : cnigita@yahoo.com
}

\begin{abstract}
Abstrak
Stunting pada pemberian nutrisi pada balita stunting dalam keluarga di Sukorejo kurang baik seperti mereka tau bahwa pemberian nutrisi pada balita itu perlu tapi mereka tidak memahami bahwa stunting adalah sebuah masalah. Pemenuhan ASI ekslusif kurang, memberikan MPASI terlalu dini, tidak memenuhi jumlah kebutuhan nutrisi sesuai usianya, pemberian makanan yang kurang bervariasi dan menyimpan makanan untuk anak lebih dari satu jam dalam suhu ruangan. Diharapkan petugas kesehatan meningkatkan mutu pelayanan konseling gizi. Keluarga dapat meningkat perilaku kesehatan balita masih menjadi masalah kesehatan utama di Indonesia. Salah satu intervensi yang paling menentukan untuk dapat mengurangi prevalensi stunting perlu dilakukan pada 1000 hari pertama kehidupan (HPK) dari anak balita yaitu praktik-praktik pemberian makanan anak balita. Hal ini dapat mewujudkan kemandirian keluarga dalam memberikan makanan pada anak stunting di rumah. Penelitian ini merupakan penelitian kualitatif yang bertujuan untuk mengidentifikasi tentang pemenuhan nutrisi pada balita stunting umur 7-23 bulan dalam keluarga di UPTD Puskesmas Sukorejo Kota Blitar. Metode pengumpulan data dilakukan dengan wawancara mendalam dan observasi kepada 5 partisipan yang semuanya terdiri dari anggota keluarga yang merawat secara langsung balita yang mengalami stunting. Hasil penelitian menyimpulkan dengan meningkatkan pemberian ASI eksklusif, memberi gizi seimbang dan melakukan kunjungan anak ke fasilitas kesehatan.
\end{abstract}

Kata Kunci : Balita, Keluarga, Nutrisi, Pemenuhan, Stunting

\section{Abstract}

Description Fulfillment of Nutrition in Toddler Stunting on Ages 7-23 Months in Families at Puskesmas Sukorejo. Stunting in infants is still a major health problem in Indonesia. One of the most decisive interventions to decreasing stunting prevalence that must we do in the first 1000 days of life of children under five, namely the practices of feeding children under five. This can create family independence in providing food to stunting children at home. This research is a qualitative study that aims to identify fulfillment of nutrition in stunting children on aged 7-23 months in the family at Pukesmas Sukorejo, Blitar City. The method of data collection was carried out by in-depth interviews and observations to 5 participants all of whose consisted of family members who directly treated stunting children. The results of the study concluded that giving nutrition to stunting toddlers in families in Sukorejo was not good like they knew that providing nutrition to infants was necessary but they did not understand that stunting was a problem. Fulfillment of exclusive breastfeeding is lacking, providing complementary feeding too early, not meeting the number of nutritional needs according to age, giving food that is less varied and storing food for children more than one hour at room temperature. Health workers are expected to improve the quality of nutrition counseling services. Families can improve health behavior by increasing exclusive breastfeeding, providing balanced nutrition and making child visits to health facilities.

Keywords: Fulfillment of Nutrition, Stunting Toddler, Family. 
Setijaningsih, Triana, dkk. Gambaran Pemenuhan Nutrisi Pada Balita Stunting Umur 7-23 Bulan Dalam Keluarga di UPTD Puskesmas Sukorejo. Journal of Borneo Holistic Health, Vol.3,

No. 1 Juni 2020 hal 1-10

\section{Pendahuluan}

Di masa balita ini, sel-sel otak manuasia berkembangn begitu pesat, sampai ada istilah golden age atau masa emas. Seorang balita diibaratkan seperti kertas putih. Tugas orang tuanya adalah menuliskan segala hal yang akan membuat tumbuh kembang si anak menjadi sehat, terarah dan bahagia. Masa balita adalah masa lima tahun pertama dalam kehidupan si anak. Segala aspek perkembangan berjalan dengan sangat pesat, mulai dari perkembangan fisik, sensorik, motoric, perkembangan mental, perkembangan social, bahasa, pengetahuan, dan spiritual mereka (Murtie, 2013)

Namun disamping itu masa ini juga merupakan masa kritis jika mereka mendapatkan perlakuan yang tidak benar, seperti cara mengasuh yang salah dan asupan nutrisi yang salah juga dapat menyebabbkan pertumbuhan dan perkembangan mereka tidak optimal bahkan terganggu dan hal ini akan berdampak pada kesehatan tubuhnya. Pada umur anak kurang dari lima tahun mereka sangat rentan mengalami sakit, karena imun dalam tubuh mereka masih belum kuat untuk melawan penyakit. Soetjiningsih (2016) mengatakan bahwa "Umur yang paling rawan adalah masa balita, terutama pada umur satu tahun pertama, karena masa itu anak sangat rentan terhadap penyakit dan sering terjadi kurang gizi”. Sehingga penting sekali untuk melakukan pencegahan terhadap penyebab penyakit yang banyak dialami oleh balita sehingga mereka dapat tumbuh dan berkembang sesuai dengan usianya.

Banyak dalam kasus balita saat ini yaitu mudahnya sakit karena kekurangan gizi kronis akibat pemberian asupan nutrisi pada anak yang tidak tepat dan kurang. Ramayulis (2018) mengatakan bahwa "Balita stunted akan memiliki tingkat kecerdasan tidak maksimal, menjadi lebih rentan terhadap penyakit, dan di masa depan dapat berisiko menurunnya tingkat produktivitas". Stunting atau pendek merupakan kondisi gagal tumbuh pada bayi (0-11 bulan) dan anak balita (12-59 bulan) akibat kekurangan gizi kronis terutama dalam 1000 hari pertama kehidupan sehingga anak terlalu pendek untuk usianya (Ramayulis, 2018). Stunting disebabkan oleh kurangnya asupan gizi dalam jangka waktu yang lama sejak konsepsi sampai anak usia 2 tahun, anak sering sakit terutama diare, campak, TBC dan penyakit infeksilainnya,keterbatasan air bersih dan sanitasi, serta ketersediaan pangan di tingkat rumah tangga rendah (Kementerian Desa, 2018).

Dari WHO dalam republika.co.id juga menyebutkan bahwa jumlah balita 
Setijaningsih, Triana, dkk. Gambaran Pemenuhan Nutrisi Pada Balita Stunting Umur 7-23 Bulan Dalam Keluarga di UPTD Puskesmas Sukorejo. Journal of Borneo Holistic Health, Vol.3,

No. 1 Juni 2020 hal 1-10

stunting di Indonesia adalah 7,8 juta dari 23 juta balita adalah penderita stunting atau sekitar 35,6\%. Sejumlah 18,5\% masuk kategori sangat pendek dan $17,1 \%$ masuk kategori pendek. Ini juga mengakibatkan WHO menetapkan Indonesia sebagai Negara dengan status gizi buruk. Dapat diperkirakan ada 162 juta balita pendek pada tahun 2012, jika tren berlanjut tanpa adanya upaya penurunan, diperkirakan akan menjadi 127 juta pada tahun 2025 . Sebanyak 56\% anak pendek hidup di Asia dan 36\% di Afrika (Infodatin, 2016).

Indonesia menduduki peringkat kelima dunia untuk jumlah anak dengan kondisi stunting lebih dari sepertiga anak berusia di bawah lima tahun di Indonesia tingginya berada dibawah rata-rata (McaIndonesia, 2013). Dari hasil Riset Kesehatan Dasar (Riskesdas) dalam Infodatin Kementerian Kesehatan RI (2016) di Indonesia Tahun 2013 adalah $37,2 \%$ jika dibandingkan tahun 2010 $(35,6 \%)$ dan tahun 2007 (36,8\%) tidak menunjukan penurunan/ perbaikan yang signfikan. Presentase tertinggi pada tahun 2013 adalah di Provinsi Nusa Tenggara Timur $(51,7 \%)$, Sulawesi Barat $(48,0 \%)$ dan Nusa Tenggara Barat (45,3\%) sedangkan presentase terendah adalah Provinsi Kepulauan Riau (26,3\%0, Di Yogyakarta $(27,2 \%)$ dan DKI Jakarta (27,5\%). Sedangkan di Provinsi Jawa
Timur sekitar lebih dari $30 \%$ balita mengalami stunting.

Pada Tahun 2015 Kementerian Kesehatan melaksanakan Pemantauan Status Gizi (PSG) yang merupakan studi potong lintang dengan sampel dari rumah tangga yang mempunyai balita di Indonesia. Hasilnya, sebesar 29\% balita Indonesia termasuk kategori pendek, dengan presentase tertinggi juga di Provinsi Nusa Tenggara Timur dan Sulawesi Barat. "Jumlah angka balita stunting berhasil diturunkan dari 29,0\% pada tahun 2015 menjadi 27,5\% pada tahun 2016," kata Menkes. Namun dari hasil Riset Kesehatan Dasar (Riskesdas) di Indonesia Tahun 2018 mengalami peningkatan kembali yaitu $30,8 \%$. Sedangkan dari beberapa riset tersebut WHO mengkategorikan prevalensi dari kasus ini adalah masih tergolong tinggi karena masih lebih dari $20 \%$.

Pada 23 April 2018 dinas kesehatan kota Blitar menemukan sebanyak 12 balita yang masuk kategori stunting atau anak yang mengalami gangguan pertumbuhan tinggi badan atau cebol akibat lahir premature dan juga kekurangan gizi, dalam sebulan terakhir. Selain dari temuan baru itu, dari Laporan Hasil Kegiatan Bulan Timbang Bulan Agustus 2018 Puskesmas Kota Blitar menyebutkan bahwa terdapat 637 balita $(8,27 \%)$ dikategorikan pendek dan sebanyak $98 \quad(1,27 \%)$ balita 
Setijaningsih, Triana, dkk. Gambaran Pemenuhan Nutrisi Pada Balita Stunting Umur 7-23 Bulan Dalam Keluarga di UPTD Puskesmas Sukorejo. Journal of Borneo Holistic Health, Vol.3,

No. 1 Juni 2020 hal 1-10

dikategorikan sangat pendek dari jumlah balita sebanyak 7707 anak. Kecamatan Sananwetan jumlah balita pendek sebanyak 174 anak $(6,11 \%)$ dan balita sangat pendek sebanyak 32 anak $(1,12 \%)$ dari jumlah balita sebanyak 2848 anak, Kecamatan Sukorejo jumlah balita pendek sebanyak 302 anak $(10,36 \%)$ dan balita sangat pendek sebanyak 65 anak $(2,23 \%)$ dari jumlah balita sebanyak 2914 anak, Kecamatan Kepanjen Kidul jumlah balita pendek sebanyak 1 anak $(0,05 \%)$ dan balita sangat pendek sebanyak 161 anak $(8,28 \%)$ dari jumlah balita sebanyak 1945 anak.

Dengan memahami tentang pola atau perilaku maupun budaya keluarga terhadap pemberian nutrisi atau perawatan kesehatan pada balita yang mengalami stunting, para tenaga kesehatan khususnya perawat di Kota Blitar akan dapat lebih mudah untuk melakukan perbaikan nutrisi pada balita yang sudah mengalami stunting.

Mengingat pentingnya mengatasi masalah kekurangan gizi kronis atau yang biasa disebut dengan "stunting" maka peneliti tertarik untuk mengidentifikasi "Gambaran Pemenuhan Nutrisi Pada Balita Stunting Umur 7-23 Bulan Dalam Keluarga di UPTD Puskesmas Sukorejo”.

\section{Metode}

Desain dalam penelitian ini menggunakan rancangan studi kasus, dengan riset kualitatif. Subyek studi kasusnya orang tua atau keluarga yang merawat anak yang terklasifikasi stunting di wilayah kerja UPTD Puskesmas Sukorejo kota Blitar sejumlah 5 responden. Pendekripsian data difokuskan tentang gambaran pemenuhan nutrisi pada balita stunting umur 7-23 bulan dalam keluarga. Lokasi Penelitian dilakukan di rumah atau tempat tinggal keluarga, dilakukan pada bulan Mei 2019. Metode yang digunakan dalam pengumpulan data dengan wawancara dan observasi kunjungan rumah. Wawancara dilakukan pada salah satu anggota keluarga untuk memperoleh data primer dengan menggunakan format wawancara sebagai alat. Data yang akan diambil meliputi pemahaman keluarga dalam memberikan nutrisi terhadap balita stunting, pemenuhan makan pada balita stunting dari segi kualitas, pemenuhan makan pada balita stunting dari segi kuantitas, dan teknik pemenuhan nutrisi pada balita stunting dalam keluarga. Observasi dilakukan untuk memperkuat data tentang pemahaman keluarga dalam memberikan nutrisi terhadap balita stunting, pemenuhan makan pada balita stunting dari segi kualitas, pemenuhan makan pada balita stunting dari segi kuantitas, dan teknikpemenuhan nutrisi pada balita stunting dalam keluarga. Observasi ini 
Setijaningsih, Triana, dkk. Gambaran Pemenuhan Nutrisi Pada Balita Stunting Umur 7-23 Bulan Dalam Keluarga di UPTD Puskesmas Sukorejo. Journal of Borneo Holistic Health, Vol.3,

No. 1 Juni 2020 hal 1-10

dilakukan pada setiap kali kunjungan. Penelitian ini, penulisan analisa data menggunakan persentase berdasarkan data hasil wawancara mendalam dan observasi dengan subjek.

\section{Hasil}

\section{Pemahaman keluarga dalam mem- berikan nutrisi terhadap balita stuting.}

Hasil penelitian didapatkan pemahaman/anggapan bahwa seluruh partisipan $=100 \%$ keluarga dalam pemberian nutrisi perlu untuk balita, akan tetapi dari semua partisipan mengatakan bahwa balita stunting bukanlah suatu masalah pertumbuhan yang harus segera ditangani. Mereka beranggapan bahwa pertumbuhan anak akan bertambah dengan sendirinya seiring berjalannya usia.

\section{Pemenuhan makan pada balita stunting dari segi kualitas \\ Dari hasil penelitian didapatkan dari} seluruh partisipan terdapat 3 partisipan $=$ $60 \%$ belum pernah mendapat konseling tentang pemberian makanan pada balita stunting, yaitu partisipan A, B, dan C. Terdapat $4=80 \%$ partisipan tetap meneruskan pemberian ASI terhadap anaknya yaitu partisipan A, B, C, dan E. Sedangkan partisipan D sudah tidak memberikan ASI kepada anaknya sejak umur 6 bulan. Dari keseluruhan partisipan $=100 \%$ tidak terdapat hambatan dalam menyusui. Seluruh partisipan $=100 \%$ tidak membersihkan putting susu sebelum menyusui. Dalam pemberian MPASI terdapat $4=80 \%$ partisipan yaitu partisipan A, B, C, dan E, memberikan MPASI mulai umur 6 bulan dan terdapat 1 $=20 \%$ partisipan yaitu $\mathrm{D}$ sudah memberikan MPASI ketika umur anak mencapai 4 bulan.

\section{Pemenuhan makan pada Balita Stunting dari segi kuantitas}

Hasil penelitian menunjukkan bahwa terdapat $4=80 \%$ partisipan yaitu partisipan A, C, D, dan E, memberikan pemenuhan makan pada balita stunting dari segi kuantitasnya kurang. Hasil wawancara dan observasi pada orang tua dalam memberikan makan pada anaknya yang berumur 12-24 bulan hanya 2-3 kali makan dalam sehari. Banyaknya nasi yang diberikan hanya 2-3 sendok makan. Pemberian makanan selingan atau memberikan makanan selingan hanya 1 kali. Sedangkan $1=20 \%$ partisipan $\mathrm{B}$ memberikan pemenuhan makan 3 kali dalam sehari dengan jumlah nasi 1 centong. Pemberian makanan selingan sebanyak 3 kali dalam sehari.

\section{Teknik pemenuhan makanan pada balita stunting \\ Dari hasil penelitian terhadap 5} partisipan didapatkan: $2=40 \%$ partisipan yaitu $\mathrm{B}$ dan $\mathrm{C}$, tidak pernah memaksa anaknya ketika makan. Pada dasarnya anak tidak pernah menolak saat diberikan makan. 
Setijaningsih, Triana, dkk. Gambaran Pemenuhan Nutrisi Pada Balita Stunting Umur 7-23 Bulan Dalam Keluarga di UPTD Puskesmas Sukorejo. Journal of Borneo Holistic Health, Vol.3,

No. 1 Juni 2020 hal 1-10

$2=40 \%$ partisipan yaitu partisipan D dan

E dengan sabar dan penuh kasih sayang menyuapi anaknya yang sulit makan hingga makanannya habis. Sedangkan $1=20 \%$ partisipan yaitu partisipan A, memaksa anaknya untuk makan ketika anaknya tidak mau makan. Semua partisipan menyimpan makanannya di atas meja makan dan ditutupi dengan tudung saji.

\section{Pembahasan}

\section{Pemahaman keluarga dalam mem- berikan nutrisi terhadap balita stuting.}

Stunting atau pendek merupakan kondisi gagal tumbuh pada bayi (0-11 bulan) dan anak balita (12-59 bulan) akibat dari kekurangan gizi kronis terutama dalam 1000 hari pertama kehidupan sehingga anak terlalu pendek untuk usianya. Kekurangan gizi terjadi sejak bayi dalam kandungan dan pada masa awal setelah bayi lahir, tetapi kondisi stunting baru nampak setelah anak berusia 2 tahun. Balita stunting akan memiliki tingkat kecerdasan tidak maksimal, menjadi lebih rentan terhadap penyakit, dan di masa depan dapat berisiko menurunnya tingkat produktivitas. Pada akhirnya, secara luas, stunting akan dapat menghambat pertumbuhan ekonomi dan meningkatkan kemiskinan. (Ramayulis, 2018).

Dari pembahasan diatas dapat disimpulkan bahwa pemahaman orangtua terhadap pemberian nutrisi pada balita stunting adalah kurang ditunjukan dengan pendapat mereka terhadap kondisi stunting bukan merupakan masalah dalam pertumbuhan anaknya. Sedangkan, dalam teori stunting atau pendek merupakan kondisi gagal tumbuh pada bayi (0-11 bulan) dan anak balita (12-59 bulan) akibat dari kekurangan gizi kronis terutama dalam 1000 hari pertama kehidupan sehingga anak terlalu pendek untuk usianya.

\section{Pemenuhan makan pada balita stunting dari segi kualitas}

WHO (2003) mengeluarkan rekomendasi tentang praktik pemberian makan bayi yang benar yaitu (Kunaepah, 2018) berikan ASI sesegera mungkin setelah melahirkan $(<1$ jam $)$ dan secara eksklusif selama 6 bulan. Berikan MPASI pada usia genap 6 bulan sambil melanjutkan ASI sampai 24 bulan. MPASI yang baik adalah yang memenuhi persyaratan tepat waktu, bergizi lengkap, cukup dan seimbang, aman dan diberikan dengan cara yang benar. Waktu pemberian MPASI yang tepat menurut Kunaepah (2018) adalah mulai usia 6 bulan (26 minggu) sampai dengan 24 bulan. Jika terlalu dini $(<4$ bulan) bisa mengakibatkan gangguan pencernaan (diare) dan alergi. Sedangkan jika lebih dari 6 bulan berisiko 
Setijaningsih, Triana, dkk. Gambaran Pemenuhan Nutrisi Pada Balita Stunting Umur 7-23 Bulan Dalam Keluarga di UPTD Puskesmas Sukorejo. Journal of Borneo Holistic Health, Vol.3, No. 1 Juni 2020 hal 1-10

kekurangan gizi (pertumbuhan dan perkembangan terganggu).

Dari pembahasan diatas dapat disimpulkan bahwa sebagian besar partisipanmemberikan ASI yang cukup dan waktu pemberian MPASI sesuai. Walaupun masih saja terdapat orangtua yang tidak mengikuti anjuran seperti: tidak meneruskan pemberian ASI setelah 6 bulan, terlalu dini memberikan MPASI kepada anaknya sebelum usia 6 bulan.

\section{Pemenuhan makan pada balita stunting dari segi kuantitas}

Menurut Hidayati (2014), balita yang berumur 6-8 bulan tetap diberikan ASI dan jenis makanan lumat seperti bubur lumat atau sayuran, daging, dan buah yang dilumatkan yaitu 2-3x sehari (2-3 sendok makan secara bertahap bertambah hingga mencapai $1 / 2$ gelas atau 125 cc setiap kali makan). Makanan selingan diberikan 1- 2x sehari berupa jus buah atau biscuit. Untuk anak umur 9-11 bulan tetap meneruskan pemberian ASI dan jenis makanan lembek atau dicincang yang mudah ditelan 3-4x sehari $(1 / 2$ gelas/mangkuk atau $125 \mathrm{cc})$ serta makanan selingan 1-2x sehari. Umur 12-24 bulan sudah boleh diberikan makanan keluarga 3-4x sehari. Makanan yang dicincang atau dihaluskan jika diperlukan dan tetap meneruskan pemberian ASI serta makanan selingan $2 \mathrm{x}$ sehari.
Menurut pendapat peneliti berdasarkan hasil wawancara dan observasi dari seluruh partisipan belum memberikan pemenuhan nutrisi atau makanan dalam jumlah dan porsi yang cukup untuk balita sesuai dengan usianya. Sehingga hal ini yang menyebabkan pertumbuhan dari balita tersebut menjadi tidak optimal.

\section{Teknik pemenuhan makan pada balita stunting}

Menurut Kunaepah (2018) salah satu cara memberikan MPASI dengan baik adalah dengan memberikan makanan dengan sabar dan tidak tergesa-gesa, memberikan perhatian disertai senyum dan kasih sayang dan salah satu cara menyimpan MPASI adalah gunakan sendok yang bersih, ambil sesuai kebutuhan bayi dan tidak memberikan makanan dalam suhu ruang lebih dari 1 jam.

Menurut peneliti berdasarkan penelitian sebagian besar partisipan sudah memberikan makan atau menyuapi anaknya dengan sabar tanpa memaksa sesuai dengan anjuran, walaupun masih ada satu partisipan yang memaksa anaknya saat memberikan makan. Dan seluruh partisipan menyimpan makanannya dalam suhu ruangan lebih dari satu jam, hal ini tidak sesuai dan dapat menyebabkan makanan yang akan diberikan pada anaknya menjadi tidak higienis dan sehat. 
Setijaningsih, Triana, dkk. Gambaran Pemenuhan Nutrisi Pada Balita Stunting Umur 7-23 Bulan Dalam Keluarga di UPTD Puskesmas Sukorejo. Journal of Borneo Holistic Health, Vol.3,

No. 1 Juni 2020 hal 1-10

\section{Kesimpulan}

Berdasarkan hasil penelitian tentang pemenuhan nutrisi pada balita stunting dalam keluarga kurang baik, dan ada beberapa hal yang perlu ditinjau kembali hal ini dapat dilihat dari jumlah partisipan 5 orang dengan karakteristik partisipan yang berbeda dan juga karakteristik lingkungan partisipan yang tidak sama dapat diambil kesimpulan sebagai berikut:

1. Pemahaman keluarga dalam memberikan nutrisi terhadap balita stunting kurang. Mereka tau bahwa pemberian nutrisi pada balita itu perlu, akan tetapi mereka tidak memahami bahwa stunting adalah sebuah masalah, mereka menganggap tinggi badan anak mereka yang pendek merupakan suatu hal yang wajar dan akan tumbuh dengan seiring berjalannya waktu.

2. Pemenuhan makan pada balita stunting dari segi kualitas dalam keluarga kurang dikarenakan pemenuhan ASI ekslusif masih ada yang belum melakukannya dengan cukup yaitu hanya memberikan sampai usia 6 bulan saja serta masih ada yang memberikan MPASI terlalu dini.

3. Pemenuhan makan pada balita stunting dari segi kuantitas dalam keluarga adalah kurang, hampir seluruh partisipan tidak memenuhi kebutuhan nutrisi sesuai dengan jumlah yang diperlukan balita sesuai dengan usianya.

4. Teknik pemenuhan makan pada balita stunting dalam keluarga adalah tidak sesuai walaupun hanya ada satu partisipan yang kurang benar dengan memaksa anak untuk makan dan tidak melakukannya dengan sabar, namun untuk teknik penyimpanannya semua partisipan tidak sesuai ditunjukan dengan membiarkan makanan dalam suhu ruangan lebih dari satu jam sehingga makanan tidak terhidang dengan higienis untuk sang balita.

5. Terdapat faktor utama yang menyebabkan kurangnya pemenuhan nutrisi pada balita stunting yaitu kurangnya pengetahuan orang tua tentang waktu, jumlah maupun jenis makanan yang diberikan kepada anak, hal ini karena kurangnya konseling dari petugas kesehatan tentang kebutuhan nutrisi pada anak. Selain itu, pemahaman orangtua yang kurang terhadap kondisi anaknya bahwa kondisi anaknya merupakan suatu masalah, hal ini menyebabkan pemberian makan pada balita stunting dari segi kualitas, kuantitas, maupun tekniknya menjadi tidak diperhatikan.

\section{Saran}

Penelitian ini, beberapa saran yang dapat diberikan antara lain: 
Setijaningsih, Triana, dkk. Gambaran Pemenuhan Nutrisi Pada Balita Stunting Umur 7-23 Bulan Dalam Keluarga di UPTD Puskesmas Sukorejo. Journal of Borneo Holistic Health, Vol.3,

No. 1 Juni 2020 hal 1-10

1. Bagi Dinas Kesehatan Kota Blitar agar dapat meningkatkan kualitas sumber daya manusia (SDM) petugas kesehatan melalui pelatihan-pelatihan yang berhubungan dengan penanganan balita stunting agar dapat ditangani dengan efektif dan efisien sehingga dapat menekan angka balita pendek (stunting) ataupun gizi buruk pada bayi dan balita.

2. Bagi tenaga kesehatan khususnya tenaga kesehatan Puskesmas yang bertugas di Poli Gizi atau Poli Anak hendaknya dapat meningkatkan kualitas mengenai penanganan pada balita stunting dengan lebih memperhatikan pedoman intervensi pada balita stunting yang sudah ada.

3. Bagi keluarga dengan anak stunting. Sebaiknya lebih meningkatkan perilaku kesehatan di tatanan rumah tangga atau keluarga seperti lebih meningkatkan pemberian ASI eksklusif, melakukan kunjungan anak ke fasilitas kesehatan untuk mengetahui tumbuh kembang dan kesehatannya serta mendapat edukasi dari petugas, serta meningkatkan pemberian nutrisi sehat dan seimbang untuk kesehatan serta tumbuh kembang anak.

4. Bagi peneliti selanjutnya diharapkan melakukan penelitian mengenai evaluasi pemenuhan nutrisi pada balita stunting dalam keluarga di tatanan Puskesmas tentang faktor-faktor penyebab balita stunting.

\section{Referensi}

Beritasatu.com (2018). Dinkes temukan 12 Balita Stunting di Kota Blitar. (Online). www.beritasatu.com/nasional/489586dinkes-temukan-12-balita-stunting-dikota-blitar.html. Diakses pada 18 September 2018.

Depkes.go.id (2017). Inilah Capaian Kinerja Kemenkes RI Tahun 20152017. (Online).Diakses pada 18 September 2018. www.depkes.go.id

Dwijayanthi, L. (2011). Ilmu Gizi Menjadi

Sangat Mudah Edisi 2. Jakarta: Buku Kedokteran EGC.

Harlinawati (2013). Konsep dan Proses Keperawatan Keluarga. Takabar (Sulawesi Selatan): Penerbit Pustaka As Salam.

Hidayati, N (2014). 1000 Hari Emas

Pertama dari Persiapan Kehamilan

Sampai Balita. Yogyakarta: Penerbit ANDI.

Indiarti, MT (2015). Nutrisi Janin dan Bayi Sejak dalam Kandungan. Yogyakarta: Parama Ilmu.

Kemenkes RI (2016). Pusat Data Dan Informasi Profil Kesehatan Indonesia 2016 - Situasi Balita Pendek. Jakarta: Pusat Data Dan Informasi Kemnkes RI. 
Setijaningsih, Triana, dkk. Gambaran Pemenuhan Nutrisi Pada Balita Stunting Umur 7-23 Bulan Dalam Keluarga di UPTD Puskesmas Sukorejo. Journal of Borneo Holistic Health, Vol.3, No. 1 Juni 2020 hal 1-10

Kementerian Desa, Pembangunan Daerah

$\begin{aligned} & \text { Tertinggal,dan } \\ & \text { (2018). Buku }\end{aligned}$ Saku Desa dalam
Penanganan
Kementerian Desanting. Pembangunan
Daerah Tertinggal, dan Transmigrasi
R.I.

Kunaepah, U, dkk (2018). Panduan Praktis

Memberi Makan Bayi (6-12 bulan).

Kendal: CV. Achmad Jaya Group.

Mca-Indonesia (2013). Stunting dan Masa

Depan Indonesia. Jakarta: Millenium

Challenge Account-Indonesia.

Murtie, A (2013). Mengajari Anak

Calistung Sejak Dini Dengan Bermain.

Jakarta : PT Gramedia Pustaka Utama.

Notoadmojo, S (2010). Metodologi

Penelitian Kesehatan. Jakarta: Rineka

Cipta.

Ramayulis,R (2018). Stop Stunting Dengan

Konseling Gizi. Jakarta: Penebar

Plus $^{+}$(Penebar Swadaya Grup).

Republika.co.id. (2018). WHO: 7,8 Juta

Balita di Indonesia Penderita

Stunting. (Online).

https://m.republika.co.id/berita/nasio

nal/umum/18/01/24/p30s85396-

who-78-juta-balita-di-indonesia-

penderita-stunting.

Riskesdas (2018). Hasil Utama Riskesdas

2018. Kementerian Kesehatan Badan

Penelitian dan Pengembangan

Kesehatan.
Setiadi (2013). Konsep dan Praktik Penulisan Riset Keperawatan Edisi 2. Yogyakarta: Graha Ilmu.

Soetjiningsih. (2016). Tumbuh Kembang Anak Edisi 2. Jakarta: Buku Kedokteran EGC.

Sugiyono. (2013). Memahami Penelitian Kualitatif. Bandung: Alfabeta.

Supariasa, I (2012). Penilaian Status Gizi. Jakarta: Buku Kedokteran EGC.

Suprajitno \& Mugianti, S (2018). Studi Kasus Sebagai Riset. Yogyakarta: Penerbit ANDI.

Sutomo \& Anggraini (2010). Menu Sehat Alami untuk Batita dan Balita. Jakarta: Demedia. 